Jackson., R. R. 1986. The biology of Phyaces comosus (Araneae: Salticidae), predatory behaviour, antipredator adaptations and silk utilization. Bulletin of the British Museum of Natural History (Zoology) 50(2): 109-116.

Based on image courtesy of the Biodiversity Heritage Library, (http://www.biodiversitylibrary.org), released subject to a Creative Commons Attribution-Noncommercial 2.5 license (http://creativecommons.org/licenses/by-nc/2.5). Use of this digital edition is subject to the same attribution and licensing. Words or characters not present in the original document have been highlighted in red. The original document was contributed to the Biodiversity Heritage Library by the Natural History Museum, London. 


\title{
The biology of Phyaces comosus (Araneae: Salticidae), predatory behaviour, antipredator adaptations and silk utilization
}

\author{
Robert R. Jackson \\ Department of Zoology, University of Canterbury, Christchurch 1, New Zealand.
}

\section{Introduction}

The salticids are generally considered to be the classic examples of cursorial hunting spiders which, instead of building webs to ensnare their prey, use acute vision to stalk, chase, and leap on active insects (Land, 1969a,b). However, the evolutionary origins of the salticids and their unique, complex eyes are poorly understood.

Recent studies of Portia (Jackson \& Blest, 1982; Jackson \& Hallas, in press), an unusual salticid genus from Africa, Asia, and Australia, suggest that questions about salticid evolution may not be as intractable as they formerly seemed. Although it moves with apparent ease across open ground and captures prey as a cursorial predator, Portia* also spins prey-capture webs and invades diverse types of alien webs to prey on the host spiders. Lacking acute vision, typical web-building spiders detect and localize prey and predators by interpreting vibratory disturbances of their webs. Using specialized movements of its legs and palps, Portia creates vibrations of the silk that deceive the host spider and assist with predation.

Portia also feeds kleptoparasitically on insects ensnared in alien webs and eats the eggs of the host spider. Eggs are an unusual prey for a salticid, since they are non-motile and salticids are generally envisaged as predators of motile arthropods.

Morphological specializations give Portia the appearance of detritus in webs, probably affording it protection from visually hunting predators. Normally, locomotion is slow and 'mechanical', rendering Portia difficult to recognize even when moving. When inactive in a web, Portia adopts a specialized posture, the cryptic rest posture, with palps retracted to beside the chelicerae and legs retracted to beside and under the body, thus obscuring the outlines of appendages. Away from webs, P. fimbriata from Queensland has a specialized means of stalking and catching typical cursorial salticids, a prey which, like Portia, has acute vision. This behaviour is unique to this species. When stalking salticids, but not other prey, P. fimbriata exaggerates the slow, mechanical nature of its locomotion, retracts its palps as in the cryptic rest posture and ceases to advance when the salticid faces. Apparently, as a result of these behaviours and the cryptic morphology of $P$. fimbriata, salticids fail to recognize $P$. fimbriata as an approaching predator.

Although typical cursorial salticids neither spin webs nor use silk in prey capture, they build silken nests in which they moult, oviposit, mate, and generally stay at night and during other periods of inactivity. A salticid in a nest is probably safe from attacks by many of its predators. However, P. fimbriata preys on salticids it locates in nests; it vibrates on the silk, enticing the salticids to come out, or waits patiently until the salticid leaves the nest spontaneously.

Although it is a specialized and complex animal, Portia has some morphological characters which are apparently pleisiomorphic (Wanless, 1978, 1984). The occurrence of pleisiomorphic traits in Portia raised the intriguing possibility that some of the behaviours of Portia are also pleisiomorphic. Recognition of this possibility led to a hypothesis, presented in detail elsewhere (Jackson \& Blest, 1982), that the Salticidae evolved from web-building spiders with poorly

*Except when ambiguity is likely to result Portia species will be referred to simply by genus i.e. Portia instead of Portia spp. 
developed vision and that acute vision evolved originally in a spider similar to Portia which became an araneophagic predator proficient at invading diverse types of webs.

It was proposed that some, but not all, of the unusual traits of Portia have been inherited from a common ancestor of Portia and all other salticids, and that these traits have been lost by most salticids but conserved in members of the genus Portia. The specialized manner in which P. fimbriata stalks ordinary salticids may have evolved secondarily and uniquely in this species.

Varied types of information are potentially useful for evaluating the Jackson \& Blest hypothesis, comparative studies of predatory behaviour and silk utilization in other salticid genera being especially important. Phyaces comosus Simon is of special interest because this small salticid, like Portia, is a highly cryptic detritus mimic; but Portia and Phyaces belong to different subfamilies (Wanless, 1986). An opportunity arose to study P. comosus, and the results of this study will be reported here.

\section{Materials and Methods}

Observations were carried out in the laboratory in Christchurch on a female P. comosus collected at Peradeniya, Sri Lanka by F. R. Wanless. Maintenance and testing procedures, terminology, and conventions used in describing behaviour were as in earlier studies (Jackson \& Hallas, in press). Various potential nest sites were provided in the form of green leaves, dry dead leaves, stems, pieces of bark, and similar objects spread about in the cage of the $P$. comosus. The spiders and insects with which $P$. comosus was tested and the types of tests for which each species was used are indicated in Table 1 (for additional information, see: Jackson \& Hallas, in press).

\section{Cryptic appearance}

Because of its unusual morphology and a specialized posture, $P$. comosus was exceedingly well concealed from human observers while standing on dead brown leaves; and on green leaves it was

Table 1. Spiders and insects (Drosophila only) used as potential prey or as sources of eggs, webs, and nests in tests with Phyaces comosus, listed alphabetically by species. A: adult spider or insect; body lengths: salticids (10-14 mm), insect (c. $2 \mathrm{~mm}$ ). CF: P. comosus put into cage with spider or insect; cage free of nests and webs. CP: spider or insect put in cage with P. comosus in its nest. CS: spins cribellate sticky web. Cu: non-salticid cursorial spider. ES: ecribellate sticky web. J: juvenile spider; body length: $c .2 \mathrm{~mm}$. NE: eggs in vacant nest. NO: nest occupied by host spider, but no eggs present. NS: non-sticky web. NSE: nest with eggs, occupied by host spider. NV: vacant nest with no eggs. Or: Oregon strain (functional wings). S: typical cursorial salticid. SS: social species; builds communal web. Vg: vestigial winged strain (flightless). WB: web-building spider. WE: eggs in vacant web. WO: web occupied by host spider. WI: insect on vacant web of S. mimosarum. WV: vacant web with no eggs.

\begin{tabular}{|c|c|c|c|}
\hline Species & Family & Description & Types of Tests \\
\hline Achaearanea sp. 1 & Theridiidae & A,WB,ES & WE,WV \\
\hline Araneus pustulosa (Walckenaer) & Araneidae & A,WB,ES & WV \\
\hline Badumna longinquus (L. Koch) & Amaurobiidae & $\mathrm{J}, \mathrm{WB}, \mathrm{CS}$ & WO \\
\hline Bavia aericeps (Simon) & Salticidae & $\mathrm{A}, \mathrm{S}$ & NE,NSE,NV \\
\hline Cambridgea antipodiana (White) & Stiphidiidae & $\mathrm{A}, \mathrm{WB}, \mathrm{NS}$ & WV \\
\hline Clubiona cambridgei (L. Koch) & Clubionidae & $\mathrm{A}, \mathrm{Cu}$ & NSE \\
\hline Dolomedes minor (L. Koch) & Pisauridae & $\mathrm{J}, \mathrm{Cu}$ & $\mathrm{CF}, \mathrm{CP}$ \\
\hline Drosophila melanogaster Or (Meigen) & Drosophiliidae & A & $\mathrm{CF}, \mathrm{CP}, \mathrm{WI}$ \\
\hline Drosophila melanogaster Vg (Meigen) & Drosophiliidae & A & $\mathrm{CF}, \mathrm{CP}, \mathrm{WI}$ \\
\hline Mopsus mormon (Karsch) & Salticidae & $\mathrm{A}, \mathrm{S}$ & NSE \\
\hline Stegodyphus mimosarum (Pavesi) & Eresidae & $\mathrm{A}, \mathrm{WB}, \mathrm{CS}, \mathrm{SS}$ & WV \\
\hline Trite auricoma (Urguhart) & Salticidae & $\mathrm{J}, \mathrm{S}$ & $\mathrm{CF}, \mathrm{CP}, \mathrm{NO}$ \\
\hline
\end{tabular}


conspicuous but unanimal-like in appearance, resembling instead a speck of dust or a minute bit of detritus.

P. comosus always stood with its legs and palps held very close to the body. Often tarsi II and III were held slightly under the body. Tarsi I tended to be just in front of the chelicerae. The palps were held very close to the front of the chelicerae, sometimes pressing against them. The femur of each palp angled up, with the remainder of the palp angling straight down. When mildly disturbed, $P$. comosus often pulled its appendages in even closer to the body and remained inactive.

\section{Locomotion}

While walking, P. comosus remained highly cryptic. Its legs moved in short, slow, barely noticeable steps and remained close to the body. Sometimes legs and palps were held closer to the body while stepping than while standing. While stepping, the spider's body rocked forward and backward in a characteristic 'bouncing' fashion (Fig. 1). Usually, the spider rocked forward-backward-forward, making a net advance of c. $1 / 2$ a body length, and a pause of 1-10 s occurred before the next bout started.

Although it occasionally leapt as far as 4 body lengths across barriers such as spaces of a few millimetres between stems, $P$. comosus usually made detours by, for example, returning to the base of the stem then walking across to the base of the other stem.

No waving of legs occurred either while stepping or during pauses between bouts of stepping; but an inconspicuous form of palp waving sometimes occurred. As the waving palps moved up and down, in matching phase, a fraction of a millimetre, they remained close to the front of the chelicerae. When chased vigourously with a brush, $P$. comosus stopped rocking and stepped more rapidly than during normal locomotion. Nevertheless, its movements continued to be much slower than the normal locomotion of typical salticids.

If forced on to a web, $P$. comosus always left immediately. Locomotion across non-sticky webs appeared laboured, and $P$. comosus adhered to cribellate and ecribellate sticky webs, eventually freeing itself after biting at threads and pulling forcefully with its legs.

\section{Nests}

The spider never built a nest unless it had access to two dead leaves, with their surfaces only a few millimetres apart, between which to spin. A thick layer of silk was spun against the surface of each leaf. On each of two opposing sides, a more sparsely woven sheet connected the two thick sheets and held the leaves together. The resulting nest had the shape of a flattened tube, c. $10 \mathrm{~mm}$ long, $7 \mathrm{~mm}$ wide and $2 \mathrm{~mm}$ deep and open at both ends. Two to six rivets (bands of silk c. $2 \mathrm{~mm}$ long, 0.5-1.0 mm wide, strung between the leaves) were widely spaced about the nest. The two leaves were very tightly bound by the silk of the rivets and the sides of the nest.

\section{Predatory behaviour}

Although Drosophila were pursued only occasionally (vestigial: 9 or 16 tests; Oregon: 3 of 12 tests), $P$. comosus readily pursued salticids (6 of 9 tests). However, essentially the same predatory behaviours occurred with both prey-types. Dolomedes were ignored by the P. comosus (8 tests).

P. comosus usually began to approach its prey, in its usual rocking gait, from $25-35 \mathrm{~mm}$ away; and its rocking movements became progressively slower and of lower amplitude as it got closer, especially as it came to within 5-10 mm. There was no tendency for $P$. comosus to behave differently depending on prey orientation. Generally, P. comosus did not wave its palps while pursuing its prey. 


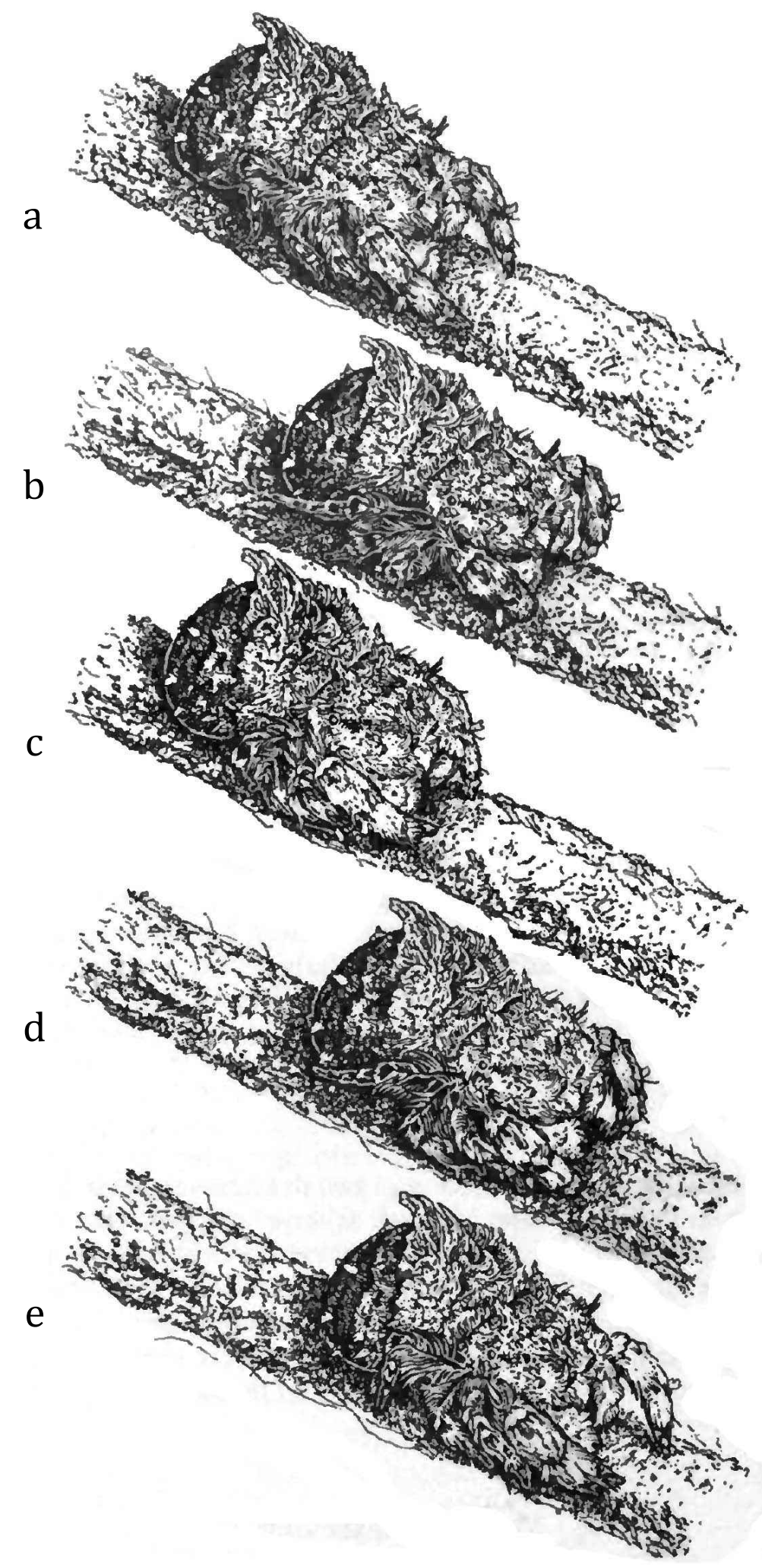

Fig. 1. Phyaces comosus Simon. Walking pattern on a stem: (a) Initial position as begins to rock body forward. (b) Maximum forward position before begins to rock backward. (c) Maximum rearward position before starting to move forward again. This position is slightly forward of the initial position. (d) Maximum forward position at the end of the second rock forward. This position is slightly beyond the maximum forward position during the first motion. Barely perceptible shifting of legs across the substrate occurred as the spider rocked forward and backward. (e) Legs are shifted forward as the spider prepares for the next bout of rocking. 


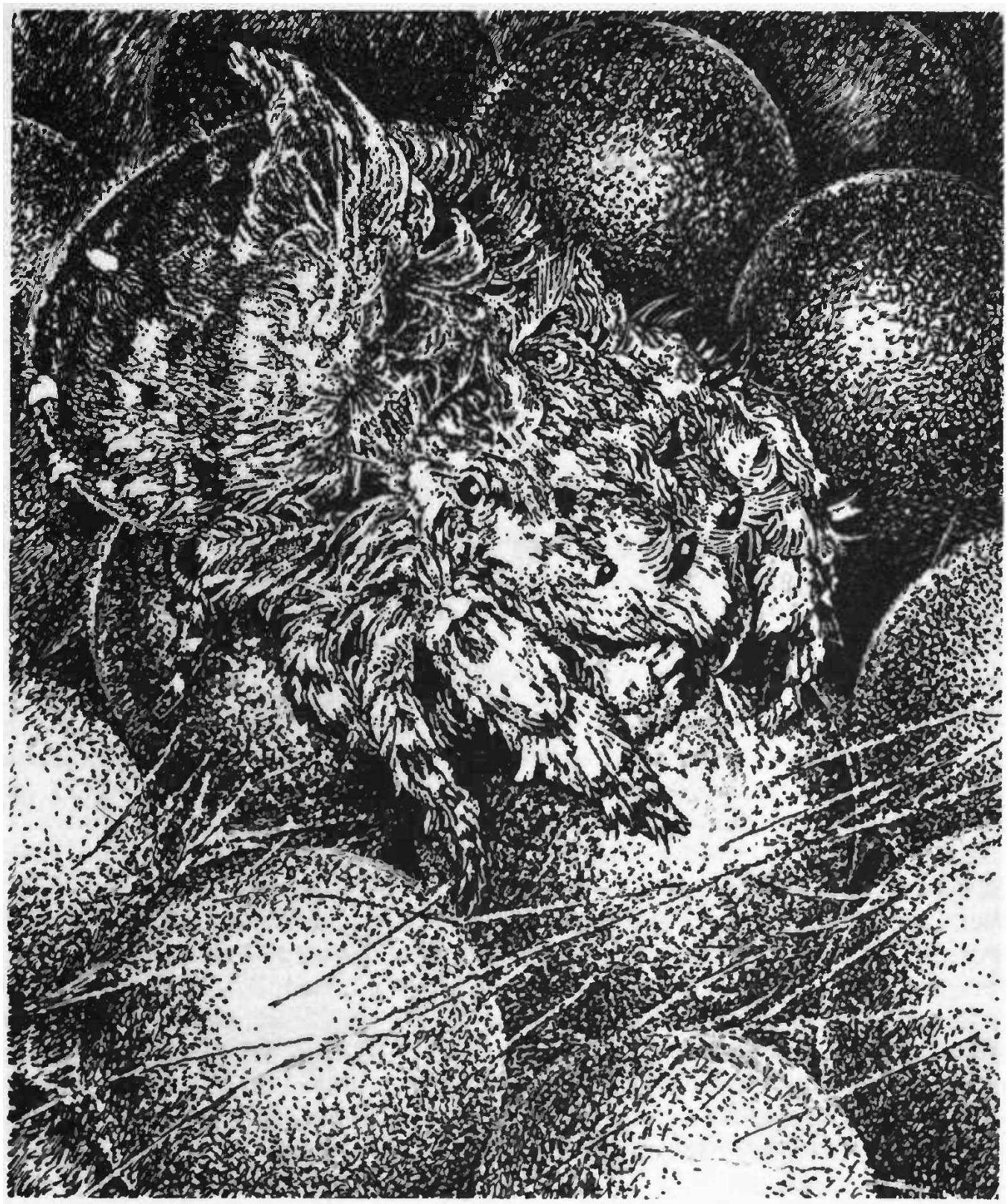

Fig. 2. Phyaces comosus Simon eating an egg of a much larger salticid (Bavia aericeps Koch). Its fangs are piercing the chorion of the egg. The eggs are almost equal in size to the P. comosus.

When $1 / 2-1$ body length away, $P$. comosus stood inactive for 1-10 s, occasionally longer, then suddenly lunged forward and grasped its prey. There were no evident preliminaries to lunging (legs were not lifted, etc.). Prey was grasped with chelicerae alone. P. comosus was observed to capture a D. melanogaster only twice (vestigial winged in both cases), but all pursued salticids were captured.

P. comosus never entered webs voluntarily and never attacked juvenile web spiders (24 tests), eggs (4 tests), or ensnared Drosophila (10 tests). If it accidently contacted the edge of a web, it moved away immediately (2 tests).

P. comosus always responded distinctively to the nests of cursorial spiders, whether occupied (8) or vacant (3). P. comosus intermittently chewed (opened and closed its chelicerae against the silk) or tugged (lifted its cephalothorax once or twice while holding onto the silk with its chelicerae) and gradually made a hole into which it placed legs I. The hole was slowly enlarged as P. comosus burrowed its way into the interior of the nest (time elapsing from initial contact with 
the nest: $0.2-3 \mathrm{~h}$ ). The 4 small juvenile salticids tested left their nests as $P$. comosus entered, but there were no evident responses by the 3 adult salticids and the one adult clubionid tested. If no eggs were present in the nest, the $P$. comosus eventually left (maximum latency: $4 \mathrm{~h}$ ); but $P$. comosus fed if eggs were present. Additional layers of silk separated eggs from the inner chamber of the nest; and to feed, $P$. comosus burrowed through this layer then walked on to and pierced an egg with its fangs. After feeding, P. comosus remained in the nest near or on the eggs for up to 6 days, sometimes feeding on one or two additional eggs. Host spiders were 8-14 mm in body length, and their eggs were almost as large as the P. comosus (Fig. 2).

\section{Discussion}

\section{Crypsis}

As a result of its specialized locomotory behaviour and its unusual morphology and posture, P. comosus is a decidedly cryptic spider, closely resembling small particles of detritus that are common on the ground and on leaves in the understory of the Sri Lankan rain-forest. By choosing dead, dried leaves for nest sites, $P$. comosus is able to move out on to a background against which it is maximally concealed when it ventures forth from its nest.

\section{Locomotion}

Functionally, the locomotory behaviour of P. comosus is comparable to that of Portia and many other highly cryptic, leaf-mimicking and stick-mimicking arthropods (Robinson, 1969). Locomotion occurs in a manner that minimizes the extent to which the animal's specialised camouflage is sacrificed, but there are major differences in the motor patterns employed. The legs and palps of Portia move in a unique 'choppy' fashion; $P$. comosus steps in a completely different forward-and-backward rocking gait.

The normal locomotion of most salticids is rapid and agile, and leaps across barriers are made readily. Portia and especially P. comosus are reluctant to leap. Portia, however, unlike P. comosus, is quite capable of moving agilely and rapidly if stressed. Although it walks faster and abandons its bouncy gait when chased vigorously, P. comosus continues to move atypically slowly for a salticid. P. comosus, like African chameleons (Guppy \& Davison, 1982) seems to be incapable of running. It is difficult to understand the evolution of an inability to retreat rapidly from predators. Perhaps crypsis is so extreme in P. comosus that rapid escape is rarely required. It would be interesting to look for structural or physiological constraints which might hinder rapid movements by P. comosus.

\section{Predatory behaviour}

The predatory behaviour of $P$. comosus consists primarily of using its normal locomotory gait to approach the prey, slowing down when close, and making a sudden lunge from close range. The manner in which $P$. comosus stalks prey, like its specialized gait during normal locomotion is consistent with crypsis and most probably maintains its concealment from visually hunting predators; but it is inefficient as a means of capturing motile insects (Drosophila). It is efficient, however, against a type of prey which is itself a visually hunting predator, namely other salticids. Both P. comosus and Portia fimbriata have a pronounced tendency to pursue salticids and a relatively weak tendency to pursue insects, suggesting that salticids are a primary prey of P. comosus. Crypsis most probably evolved initially as an antipredatory rather than a predatory adaptation, antipredatory crypsis possibly preadapting both species as specialized predators on salticids. Compared to P. comosus, the behaviour used by P. fimbriata when pursuing a salticid as prey is more discrete from normal locomotion and from predatory behaviour used against other types of prey. With its shorter legs and more hirsute body, $P$. comosus may be a more thoroughly cryptic spider than $P$. fimbriata. Thus it might have less to gain by 'refinements' of the types used by P. fimbriata. Also the normally larger salticid prey of the larger (c. $10 \mathrm{~mm}$ ) P. fimbriata may 
tend to have vision of greater acuity than the minute salticids with minute eyes preyed on by the small $P$. comosus in the dimly lit understory of the forest (Blest, in press).

Considering the differences in the behaviour of $P$. fimbriata and P. comosus when pursuing salticids and the disparate taxonomic placements of these two species, specialized stalking of salticids most likely evolved convergently. Cursorial salticids are extraordinarily abundant in the Queensland habitat of P. fimbriata, and this may have been a major factor favouring the evolution of specialized predation on salticids by this species. Salticids did not seem comparatively abundant in the habitat of $P$. comosus, although small salticids easily could have been overlooked. P. comosus and P. fimbriata have another behaviour in common, which is shared by all studied Portia: feeding on the eggs of other spiders. Differences in the oophagic behaviours of Portia and $P$. comosus are evidently related to differences in the sizes of these spiders. Portia either bites into the egg sac and eats out its contents as a single entity, or it opens up egg sacs, rakes out the eggs, and feeds on them one at a time. The much smaller P. comosus bores into egg sacs, stands on the eggs, and eats them one at a time.

Salticids and clubionids will attack if they detect intruders at the nest (Eberhard, 1974; Jackson, 1976; Pollard, 1983). However, with its small size, stealthy movements, and cryptic morphology, P. comosus avoids attracting the attention of and eliciting attacks from the maternal spider. As a distinctly araneophagic spider, Portia is in frequent proximity of spider egg sacs, and this was probably an important factor in the evolution of oophagy in this genus. Oophagy probably evolved independently in P. comosus, crypsis and small size being important preadaptations. Each egg of a large spider is almost as large as the $P$. comosus, and the egg mass in a single egg sac is a veritable bonanza. The adaptive advantage of oophagic behaviours for $P$. comosus are readily apparent.

\section{Evolutionary implications}

To evaluate the proposal that the unique combination of behaviours that occurs in Portia is partially a reflection of salticid ancestry, it will be important to ascertain the distribution of these behaviours within the Salticidae. Detritus mimicry, oophagy and specialized predation on salticids are three unusual characteristics that probably evolved independently in P. comosus and Portia. However, web-building and web-invading with the use of aggressive mimicry, which were proposed as characteristics of salticid ancestors, do not occur in P. comosus, suggesting that these are evolutionarily conservative characters, as implied by the Jackson \& Blest hypothesis.

A more exhaustive study of Phyaces would be interesting; but the prospects for this are dim because of the remoteness, for most arachnologists, of the natural habitats of these spiders and the considerable difficulty of locating Phyaces in the field, which is at least partly due to its mimicry of detritus and its small size.

\section{Acknowledgements}

Financial support for field studies in Sri Lanka was provided by National Geographic Society Grant 2330-81. Grants from the University Grants Committee of New Zealand assisted with laboratory studies in Christchurch. The drawings used to illustrate behaviours of $P$. comosus were prepared by Richard Lovell-Smith whose high professional standards as an artist, meticulous attention to detail, and dedicated interest in the study deserve special acknowledgement. Fred Wanless, Susan Hallas, and Mary Whitehouse are gratefully acknowledged for their comments on the manuscript.

\section{References}

Blest, A. D. In press. Retinal mosaics of the principal eyes of jumping spiders (Salticidae) in some Neotropical habitats: optical trade-offs between size and habitat illuminances. J. Comp. Physiol.

Eberhard, W. G. 1974. Maternal behaviour in a South American Lyssomanes. Bull. Br. Arachnol. Soc. 3: 51.

Guppy, M. \& Davison, W. 1982. The hare and the tortoise: metabolic strategies in cardiac and skeletal muscles of the skink and the chameleon. J. exp. Zool. 220: 289-295. 
Jackson, R. R. 1976. Predation as a selection factor in the mating strategy of the jumping spider Phidippus johnsoni (Salticidae, Araneae). Psyche 83: 243-255.

Jackson, R. R. \& Blest, A. D. 1982. The biology of Portia fimbriata, a web-building jumping spider (Araneae, Salticidae) from Queensland: utilization of webs and predatory versatility. J. Zool. (Lond.) 196: 255-293.

Jackson, R. R. \& Hallas, S. E. A. In press. Comparative biology of Portia africana, P. albimana, P. fimbriata, P. labiata, and $P$. schultzi, araneophagic, web-building jumping spiders (Araneae, Salticidae): utilization of webs, predatory versatility and intraspecific interactions. N.Z. J. Zool.

Land, M. F. 1969a. Structure of the retinae of the principal eyes of jumping spiders (Salticidae: Dendryphantinae) in relation to visual optics. J. exp. Biol. 51: 443-470.

Land, M. F. 1969b. Movements of the retinae of jumping spiders (Salticidae: Dendryphantinae) in response to visual stimulti. J. exp. Biol. 51: 471-493.

Pollard, S. D. 1983. Egg guarding by Clubiona cambridgei (Araneae: Clubionidae) against conspecific predators. J. Arachnol. 11: 323-326.

Robinson, M. H. 1969. Defenses against visually hunting predators. In: Dobzhansky, T., Hecht, M. K. \& Steere, W.C. (Eds.) Evolutionary Biology 3: 225-259. New York: Meredith.

Wanless, F. R. 1978. A revision of the spider genus Portia (Araneae: Salticidae). Bull. Br. Mus. nat. Hist. (Zool.) 34: 83124.

Wanless, F. R. 1984. A review of the spider subfamily Spartaeine nom. n. (Araneae: Salticidae) with descriptions of six new genera. Bull. Br. Mus. nat. Hist. (Zool.) 46: 135-205.

Wanless, F. R. 1986. A revision of the spider genus Phyaces (Araneae: Salticidae). Bull. Br. Mus. nat. Hist. (Zool.) 50: 103-108. 